\title{
A breast mass in a 56-year-old man
}

\author{
Derek R. MacFadden MD, Wayne L. Gold MD, Susan E. Richardson MD, Paul E. Bunce MD
}

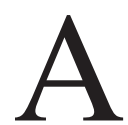

56-year-old man living in Toronto, Ontario, presented to his family physician after finding a lump in his right breast on self-inspection. He described a onemonth history of pressure and tenderness at the site of the mass. No other lumps were detected, and there was no history of fever, sweats, weight loss or previous trauma to the breast. He had a history of obstructive sleep apnea, took no medications and did not use recreational or injection drugs. The patient had no relevant family history and no contacts with people who were ill. His history of travel was limited to his cottage in central Ontario.

On examination, a $3-\mathrm{cm}$ mass that extended medially was palpable in the retroareolar area of the patient's right breast. The mass was rubbery, nontender and did not appear to be tethered to the overlying skin, which was intact. No axillary lymphadenopathy was detected. The left breast and the remainder of the general examination were normal.

\section{What is the most common cause of a breast mass in a man?}

a. Gynecomastia

b. Breast carcinoma

c. Benign fibrocystic changes

d. Inflammatory/infectious diseases of the breast

e. Lymphoma

Gynecomastia is the most common cause of combined unilateral and bilateral breast mass(es) in

Box 1: Differential diagnosis of a breast mass in a man $^{1-3}$

- Gynecomastia: $72 \%-83 \%$ of cases

- Malignant neoplasms (including carcinoma and lymphoma): $4 \%-13 \%$ of cases

- Inflammation or infection: $2 \%-3 \%$ of cases

- Other benign diseases of the breast, such as fibrocystic disease, duct papilloma, lipoma or epidermoid cysts: $10 \%-13 \%$ of cases men (Box 1).$^{1-4}$ Clinically, gynecomastia usually presents as a concentric retroareolar rubbery mass. ${ }^{4}$ This patient's mass was atypical of gynecomastia as it extended medially in an asymmetric fashion. Given the possibility of a malignant cause, the patient was referred for further evaluation to a rapid diagnostic clinic for breast cancer.

At the clinic, the patient received a mammogram, ultrasonography and a core biopsy of the mass. Mammography showed a well-defined $2.5-\mathrm{cm}$ mass located within the right breast (Figure 1). No calcifications were present. Ultrasonography confirmed these findings and did not detect any substantial regional lymphadenopathy. A core biopsy and tissue staining suggested a fungal cause (Figure 2 and Appendix 1, available at www.cmaj.ca/lookup/suppl/doi:10.1503/cmaj .110953/-/DC1.), but no specimen was sent for culture. Based on the results of the biopsy, the patient was referred to an outpatient clinic for infectious diseases for further evaluation and management of the condition.

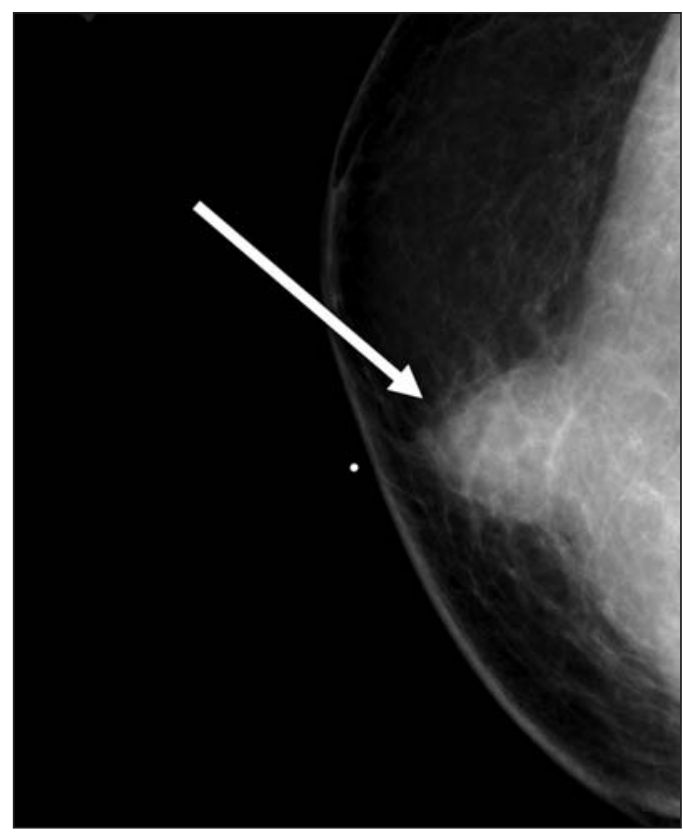

Figure 1: Mammogram of the right breast of a 56year-old man (right craniocaudal view) showing a well-defined, noncalcified lesion (arrow).
Competing interests: Susan Richardson has received grants from Allergen NCE and Pfizer Canada. No other competing interests were declared.

This article has been peer reviewed.

Correspondence to: Dr. Paul E. Bunce, p.bunce@utoronto.ca

CMAJ 2011. DOI:10.1503 /cmaj.110953 


\section{What fungal pathogen is the most likely cause of this breast mass?}

\author{
a. Blastomyces dermatitidis \\ b. Coccidioides immitis \\ c. Cryptococcus neoformans \\ d. Histoplasma capsulatum
}

Based on the pathologists's interpretation of the biopsy specimen, which showed granulomatous inflammation and large yeast forms, the organism most likely responsible for this patient's breast mass was either Blastomyces dermatitidis or Cryptococcus neoformans. Despite further review by a medical microbiologist, a more definitive diagnosis could not be reached using morphology alone. Coccidioides immitis is an unlikely suspect, given the absence of characteristic morphology (endosporulating spherules) and lack of travel to

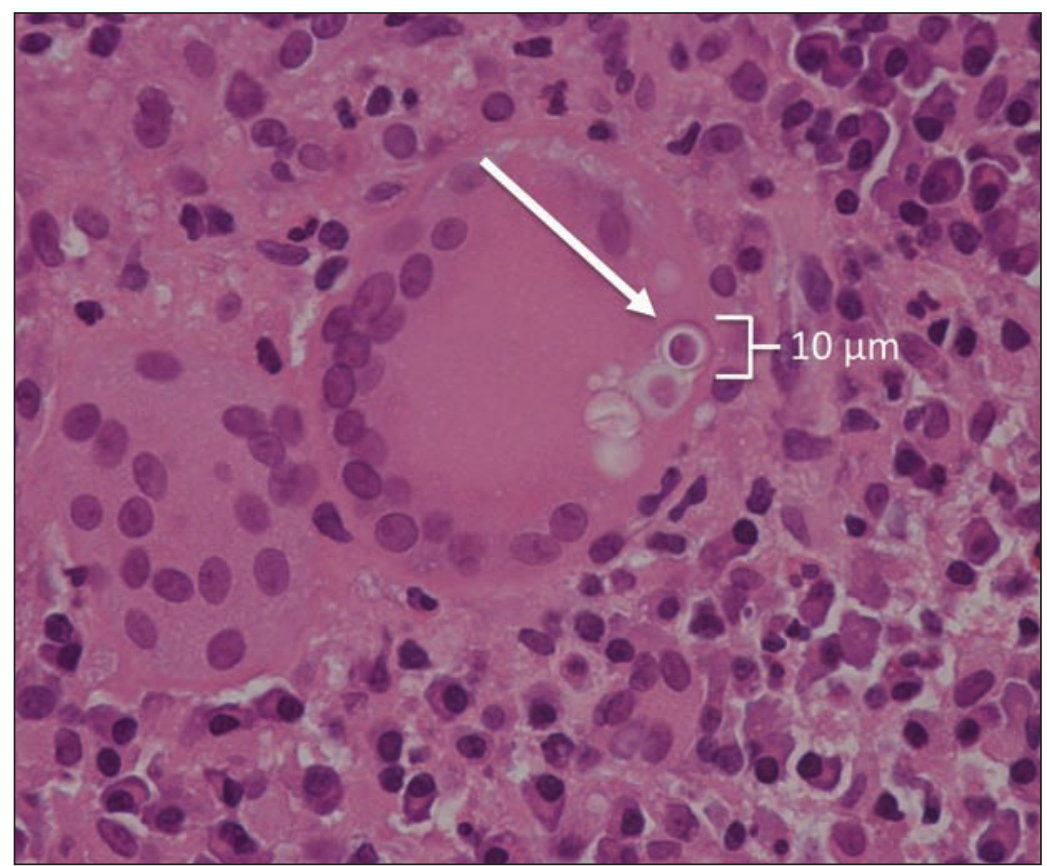

Figure 2: Micrograph of a specimen from a tissue biopsy from the patient's right breast ( $600 \times$ magnification, hematoxylin and eosin stain) showing multinucleated giant cells engulfing yeast forms (arrow). locations where this organism is endemic, such as the southwestern United States and Mexico. Histoplasma capsulatum is also not a candidate because of its smaller size (Table 1). ${ }^{5-7}$

\section{How would you identify the organism responsible?}

a. Repeat biopsy for culture.

b. Treat empirically based on the limited differential diagnosis.

c. Test the specimen further, such as by polymerase chain reaction, to identify the organism

d. Observe the patient over time and monitor for spontaneous resolution.

To avoid further invasive testing, a polymerase chain reaction test (amplifying the internal transcribed spacer of the fungal ribosomal DNA using ITS3 and ITS4 primers) was done after digestion and extraction of the paraffin-embedded specimen, and a positive result was found. ${ }^{8}$ The amplicon was sequenced, and $B$. dermatitidis was confirmed. A second biopsy for culture would be a reasonable alternative if polymerase chain reaction testing were not readily available.

Given the limited differential diagnosis of blastomycosis and cryptococcosis, empiric treatment would be less ideal, as the recommended first-line antifungal agents for cryptococcosis and blastomycosis differ, ${ }^{9,10}$ and a diagnosis of extrapulmonary cryptococcal infection would raise the issue of whether a lumbar puncture was required to exclude infection of the central nervous system. Clinical monitoring for resolution should not be performed as the patient would be at risk of the disease progressing.

A contrast-enhanced computed tomographic (CT) scan of the thorax was done to determine the extent of tissue invasion and to assess for a primary pulmonary source of infection (Figure 3). The image showed the right breast mass, with no evidence of parenchymal lung disease. Serologic testing for human immunodeficiency virus was

Table 1: Characteristics of common pathogenic fungal organisms ${ }^{5-7}$

\begin{tabular}{|lcll|}
\hline Organism & Diameter, $\mu \mathrm{m}$ & \multicolumn{1}{c|}{ Morphology } & Endemic regions \\
\hline $\begin{array}{l}\text { Cryptococcus } \\
\text { neoformans }\end{array}$ & $5-10$ & $\begin{array}{l}\text { Pleomorphic (round, oval or elliptical), } \\
\text { thin walled, narrow-based budding }\end{array}$ & Worldwide \\
\hline $\begin{array}{l}\text { Coccidioides } \\
\text { immitis }\end{array}$ & $20-200$ & Endosporulating spherules & $\begin{array}{l}\text { Southwestern United States, northern Mexico, } \\
\text { parts of Central and South America }\end{array}$ \\
\hline $\begin{array}{l}\text { Blastomyces } \\
\text { dermatitidis }\end{array}$ & $8-15$ & $\begin{array}{l}\text { Spherical or oval cells, doubly contoured } \\
\text { refractile cell walls, broad-based budding }\end{array}$ & $\begin{array}{l}\text { North America, east of the Mississippi (rarely } \\
\text { outside North America) }\end{array}$ \\
\hline $\begin{array}{l}\text { Histoplasma } \\
\text { capsulatum }\end{array}$ & $2-5$ & Narrow-based budding & $\begin{array}{l}\text { Ohio and Mississippi River Valleys (less common } \\
\text { outside North America) }\end{array}$ \\
\hline
\end{tabular}


negative. The patient was given itraconazole with a planned duration of 6-12 months. At six months follow-up, the mass was no longer detectable by clinical examination. Treatment continued for three months thereafter.

\section{Discussion}

Blastomycosis is a pyogranulomatous infection caused by the dimorphic fungus $B$. dermatitidis. This organism is saprophytic (it derives nourishment from decaying organic matter) and preferentially inhabits moist soils, typically adjacent to waterways. Blastomycosis is predominantly a North American disease, occurring most frequently in regions near bodies of water, such as states adjacent to the Ohio and Mississippi River basins or the states and provinces near the Great Lakes. The route of entry is usually via the lungs, when spores released from soil or decomposing organic matter are inhaled. Rarely, cutaneous inoculation can occur through trauma or animal bites. Disease can occur in both immunocompetent and immunocompromised hosts, although disseminated disease is more common in the latter. ${ }^{5}$

\section{Epidemiology}

Annual North American incidence rates are highest in two hyperendemic regions: Kenora, Ont., (117.2 cases/100 000 population) and Vilas County, Wisconsin ${ }^{11}$ (100 cases/100 000 population). In Ontario, the north has the highest annual incidence (2.44 cases/100 000 population), and the Toronto area has the second highest annual incidence ( 0.26 cases $/ 100000$ population). ${ }^{11}$ The central east region of the province has an annual incidence rate of 0.08 cases per 100000 population. ${ }^{11}$ The high incidence rates in Toronto could reflect autochthonous acquisition (primary infection occurring in Toronto) or diagnoses within the Toronto area with acquisition of the fungus elsewhere. It is possible that our patient acquired his infection at either his cottage or at his home.

\section{Clinical features}

Patients with blastomycosis can appear along a spectrum of illness from minimally symptomatic, localized disease to fulminant and disseminated presentations. Pulmonary blastomycosis can be acute or chronic, and can present as airspace disease, mass lesions, interstitial lung disease or cavitary disease on radiographic imaging. ${ }^{5}$ There is pulmonary involvement in $91.4 \%$ of cases of blastomycosis, but other organ systems may also be affected (e.g., the skin [18.1\% of cases] and bone [4.3\% of cases], the genitourinary system $[1.8 \%$ of cases] and the central nervous system $[1.2 \%$ of cases] $) .{ }^{12}$
Cutaneous disease can arise from dissemination from a primary pulmonary focus of infection or, more rarely, through primary cutaneous inoculation. As many as 50\% of patients with presumed secondary cutaneous involvement will have no findings on radiographic imaging of the chest. ${ }^{13}$ Our patient's presentation could have been the result of an asymptomatic primary pulmonary route of infection with secondary dissemination to the subcutaneous tissues of the breast. Classically, the skin lesions of blastomycosis are verrucous in nature, but they can also be ulcerative or appear as subcutaneous nodules. ${ }^{5}$

Blastomycosis of the breast has been reported rarely in the literature (fewer than 10 cases reported in the past 50 years). ${ }^{14-17}$ Most cases describe either a primary pulmonary route of infection or an unclear mechanism of infection, as seen in our patient.

\section{Diagnosis}

The diagnosis of blastomycosis is usually made by one of three methods: histopathologic examination of tissue specimens, direct microscopy and fungal culture or, less commonly, molecular testing (polymerase chain reaction).

Culture and staining of specimens from the respiratory tract has a sensitivity of $75 \%$ for an individual sputum specimen in patients with pulmonary blastomycosis. These methods allow for diagnosis by observation of yeast forms on direct

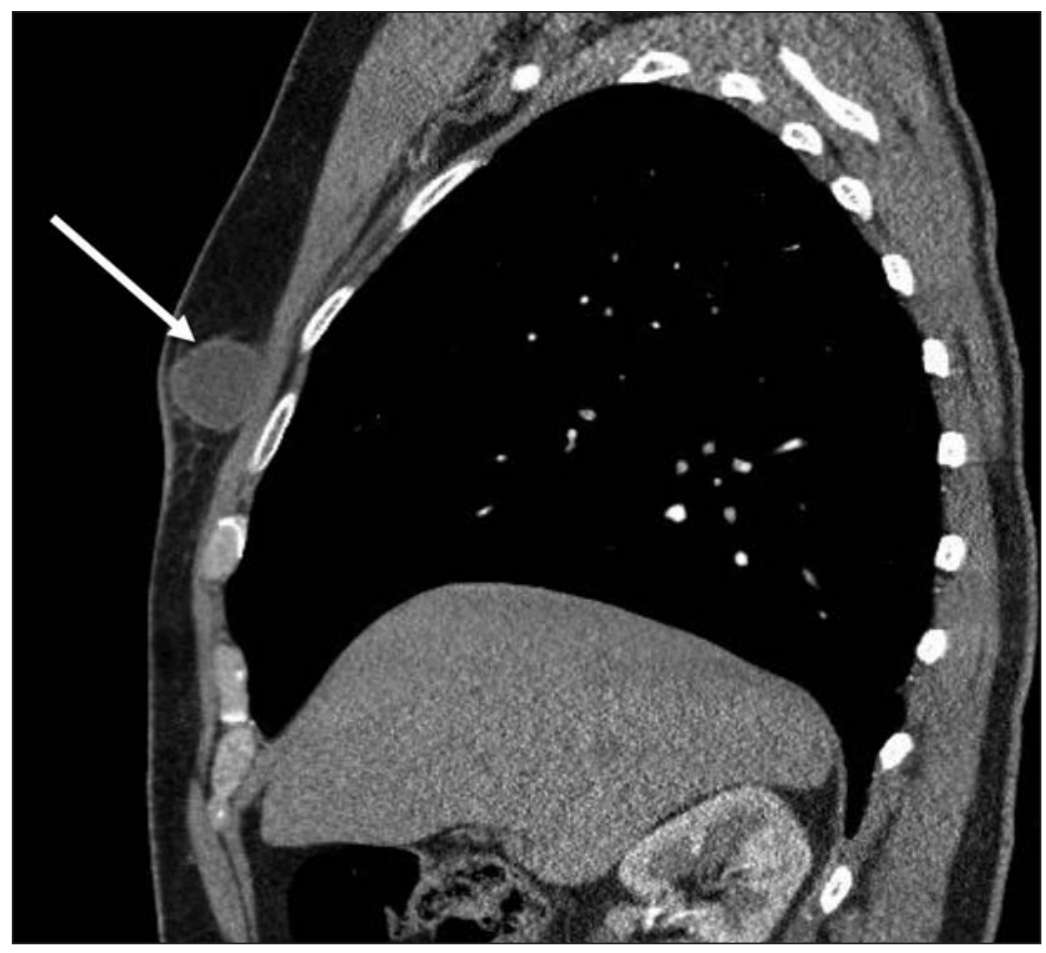

Figure 3: Contrast-enhanced computed tomography image of the patient's thorax (sagittal view) showing a well-defined mass in the right breast (arrow). The mass does not show extension to the underlying chest wall. 
examination and by growth of a mould with typical features of $B$. dermatitidis. ${ }^{5,18}$

Various types of polymerase chain reaction testing (conventional, real-time or multiplex) can be used to detect and amplify fungal DNA targets, with subsequent confirmation using sequencing or the binding of specific probes. The combination of polymerase chain reaction testing and sequencing assay should be validated for all laboratories using such methods on diagnostic specimens. For our patient, molecular identification avoided the need for further invasive tissue sampling.

Antigen or antibody tests, though available, have limited utility owing to their low specificity secondary to cross reactivity with other fungal species (most commonly H. capsulatum). ${ }^{5}$ In regions where histoplasmosis and blastomycosis are not coendemic, these assays may be of greater diagnostic use.

\section{Treatment}

Optimal treatment for blastomycosis depends on the site and severity of disease. ${ }^{9}$ Reports of expert committees and expert opinion recommend formulations of amphotericin B as a starting point for severe or disseminated disease, including those that involve the central nervous system and in patients with impaired immune function. ${ }^{9}$ The success rates of treatment with amphotericin B in moderate to severe disseminated disease range from $70 \%$ to $91 \%$. ${ }^{9}$

For continuation therapy, and for mild to moderate pulmonary and disseminated disease, itraconazole is the preferred antifungal agent based on nonrandomized clinical studies. ${ }^{9}$ The rate of success for treatment of mild to moderate disease with itraconazole approaches $95 \%$. $^{9}$

Standard doses of ketoconazole and fluconazole show reduced activity against $B$. dermatitidis, and voriconazole lacks sufficient evidence to support its first-line use..$^{59}$ Echinocandins, such as caspofungin or micafungin, have poor activity against $B$. dermatitidis and should not be used. ${ }^{9}$ For patients such as ours, who have mild extrapulmonary disease, it is recommended that treatment last at least six months; this can be continued for up to one year, depending on the patient's response to therapy. ${ }^{9}$

\section{Summary}

The experience of our patient highlights several important points. First, infectious causes should be considered in the differential diagnosis of subcutaneous masses, including breast masses, and appropriate microbiologic investigations should be requested to confirm diagnoses. Second, blastomycosis, an endemic mycosis in several parts of Canada, can be diagnosed through multiple methods that include the histopathologic exam- ination of tissue specimens, direct microscopy and fungal culture, and molecular-based techniques. For our patient, a molecular-based technique allowed for a definitive diagnosis and avoided repeated invasive tissue sampling. Finally, itraconazole is an effective treatment for mild to moderate disease in patients who are not substantially immunocompromised.

\section{References}

1. Singh R, Anshu, Sharma SM, et al. Spectrum of male breast lesions diagnosed by fine needle aspiration cytology: a 5-year experience at a tertiary care rural hospital in central India. Diagn Cytopathol 2010 Nov. 12 [Epub ahead of print].

2. Wauters CA, Koolstra BW, de Klevit-van der Heijden IM, et al. Is cytology useful in the diagnostic workup of male breast lesions? A retrospective study over a 16-year period and review of the recent literature. Acta Cytol 2010;54:259-64.

3. Das DK, Junaid TA, Mathews SB, et al. Fine needle aspiration cytology diagnosis of male breast lesions. A study of 185 cases. Acta Cytol 1995;39:870-6.

4. Braunstein GD. Clinical practice. Gynecomastia. $N$ Engl J Med 2007;357:1229-37.

5. Saccente M, Woods GL. Clinical and laboratory update on blastomycosis. Clin Microbiol Rev 2010;23:367-81.

6. Kaufman L. Laboratory methods for the diagnosis and confirmation of systemic mycoses. Clin Infect Dis 1992;14(Supp 1):S23-9.

7. Guarner J, Brandt ME. Histopathologic diagnosis of fungal infections in the 21st century. Clin Microbiol Rev 2011;24:247-80.

8. Kakkar F, Gharabaghi F, Richardson S. Utility of a pan-fungal PCR for identification of fungi from fresh and fixed tissue [abstract]. 48th Annual ICAAC/IDSA 46th Annual Meeting; 2008 Oct. 25-28; Washington (DC).

9. Chapman SW, Dismukes WE, Proia LA, et al. Clinical practice guidelines for the management of blastomycosis: 2008 update by the Infectious Diseases Society of America. Clin Infect Dis 2008;46:1801-12.

10. Perfect JR, Dismukes WE, Dromer F, et al. Clinical practice guidelines for the management of cryptococcal disease: 2010 update by the Infectious Disease Society of America. Clin Infect Dis 2010;50:291-322.

11. Morris SK, Brophy J, Richardson SE, et al. Blastomycosis in Ontario, 1994-2003. Emerg Infect Dis 2006;12:274-9.

12. Chapman SW, Lin AC, Hendricks KA, et al. Endemic blastomycocis in Mississippi: epidemiological and clinical studies. Semin Respir Infect 1997;12:219-28.

13. Mason AR, Cortes GY, Cook J, et al. Cutaneous blastomycosis: a diagnostic challenge. Int J Dermatol 2008;47:824-30.

14. Propeck P, Scanlan K. Blastomycosis of the breast. AJR Am J Roentgenol. 1996;166:726.

15. Farmer C, Stanley MW, Bardales RH, et al. Mycoses of the breast: diagnosis by fine-needle aspiration. Diagn Cytopathol 1995; $12: 51-5$

16. Seymour EQ. Blastomycosis of the breast. AJR Am J Roentgenol 1982;139:822-3.

17. Salfelder K, Schwarz J. Mycotic "pseudotumors" of the breast. Arch Surg 1975;110:751-4.

18. Martynowicz MA, Prakash UB. Pulmonary blastomycosis: an appraisal of diagnostic techniques. Chest 2002;121:768-73.

Affiliations: From the Department of Medicine (MacFadden, Gold, Bunce) and the Department of Laboratory Medicine and Pathobiology (Richardson), University of Toronto, Toronto, Ont; the Division of Infectious Diseases (Gold, Bunce), University Health Network, Toronto, Ont; and the Division of Microbiology (Richardson), Department of Paediatric Laboratory Medicine, Hospital for Sick Children, Toronto, Ont.

Contributors: All four authors made substantial contributions to this work. Derek MacFadden, Wayne Gold and Paul Bunce were involved in the clinical care of this patient. Derek MacFadden, Wayne Gold, Susan Richarson and Paul Bunce conceived the report. Derek MacFadden and Paul Bunce conducted the review of the literature. Derek MacFadden wrote the initial version of the manuscript. Derek MacFadden, Wayne Gold, Susan Richardson and Paul Bunce edited the manuscript and approved the final version submitted for publication. 